\title{
Nanoshell-Containing Carbon Cathode Catalyst for Proton Exchange Membrane Fuel Cell from Herbaceous Plants Lignin
}

\author{
Naokatsu Kannari, Machiko Takigami, Takuya Maie, Hiroyuki Honda, Sayaka Kusadokoro, \\ Jun-ichi Ozaki* \\ Department of Chemical and Environmental Engineering, Gunma University, Kiryu, Japan.

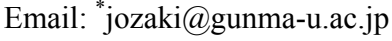 \\ Received March 19 ${ }^{\text {th }}, 2013$; revised April 19 ${ }^{\text {th }}, 2013$; accepted April 26 $6^{\text {th }}, 2013$ \\ Copyright (C) 2013 Naokatsu Kannari et al. This is an open access article distributed under the Creative Commons Attribution License, \\ which permits unrestricted use, distribution, and reproduction in any medium, provided the original work is properly cited.
}

\begin{abstract}
Nanoshell-containing carbon (NSCC) is one of the Pt-surrogate catalysts for proton exchange membrane fuel cell (PEMFC) invented by us to promote oxygen reduction reaction (ORR), the cathode reaction of the cell. In the present study, we selected one of renewable resources, lignin from herbaceous plants as the carbon precursor for NSCC. The lignin was admixed with cobalt phthalocyanine $(\mathrm{CoPc})$, the nanoshell (NS) forming catalyst, and then carbonized at $1000^{\circ} \mathrm{C}$. Transmission electron microscopy and X-ray diffraction studies confirmed the formation of NS structure. The ORR activity of the prepared NSCC increased with the amount of CoPc, and the activity of lignin-based NSCC was higher than that of phenol-formaldehyde resin-based NSCC with the same amount of CoPc added. Surface analysis by $\mathrm{X}$-ray photoelectron spectroscopy revealed no metal species on the NSCC but higher N/C ratio for the lignin-based NSCC by two folds. This study shows the possibility of lignin as a precursor of NSCC cathode catalyst for PEMFC.
\end{abstract}

Keywords: Proton Exchange Membrane Fuel Cell; Oxygen Reduction Reaction; Lignin; Nanoshell-Containing Carbon

\section{Introduction}

The proton exchange membrane fuel cell (PEMFC) is one of the most promising technologies, however, the high cost of platinum used to catalyze the cathode oxygen reduction reaction (ORR) restricts the commercialization of PEMFCs. To solve the problem, the authors developed electrochemically active carbon materials, named nanoshell-containing carbon (NSCC). Nanoshell (NS) is a type of nanocarbon, whose structure is hollow spherical shape with a diameter of $20-50 \mathrm{~nm}$ by stacking of hexagonal carbon layers. We have prepared NSCCs using synthetic polymer based materials such as furan resin [1,2], oxine-formaldehyde resin [3], furfuryl alcohol [4-6] and phenol-formaldehyde resin $[7,8]$. In the reports we have mentioned that NS structure and nitrogen played important roles to improve ORR activities of carbon materials.

Another challenging topic in material and ecological science is to convert plant-based materials to highly value added materials. Lignin (LG) is one of the most

${ }^{*}$ Corresponding author. abundant organic compounds on Earth exceeded only by cellulose. It is a main component of woods and herbaceous plants and has unique properties. Most of LG is consumed as fuel, however, LG is used as raw materials for several chemicals, such as vanillin, DMSO, ethanol, xylitol sugar and humic acid. As LG is a sustainable material, researches to use LG in wide area have been conducted, such as natural antioxidants [9-11], adherent [12], waste water treatment $[13,14]$ hydrogen electrosorption [15], and bipolar plates [16]. However, there are no reports to use LG as a source in the production of NSCC or other types of catalysts for PEMFC. LG seems to have some advantages for the use of cathode catalysts in the following points:

1) Contains much aromatic hydrocarbon;

2) Contains some nitrogen [17].

Using LG as a precursor of carbon materials, LG was mixed with cobalt phthalocyanine $(\mathrm{CoPc})$ and characterizations of the materials were carried out. Our interests were:

1) Whether LG forms nanoshell structure or not in the presence of CoPc. 
2) Whether carbon materials prepared from LG show high ORR activity or not.

\section{Experimental}

\subsection{Sample Preparation}

Two ways were used to mix carbon precursor with $\mathrm{CoPc}$; mixing by ball milling in solid state and mixing in solution state for LG and phenol-formaldehyde resin, respectively.

\subsubsection{Lignin-Based Samples}

LG separated from herbaceous plants by alkaline delignification and commercialized under the name of Granit Lignin Powder, Protobind 2000 (Pb2000) was provided by Granit SA, Switzerland. Elemental composition of the material is presented in Table 1. As shown in Table 1, $\mathrm{Pb} 2000$ contained some metals, phosphorus and nitrogen. To remove the metals, $2.5 \mathrm{~g}$ of $\mathrm{Pb} 2000$ was mixed with $100 \mathrm{~mL}$ of $1 \mathrm{M}$ hydrochloric acid and stirred at $70^{\circ} \mathrm{C}$ for $2 \mathrm{~h}$. Then the mixture was filtered with a membrane filter with a pore size of $5 \mu \mathrm{m}$. The procedure was repeated three times and the mixture was thoroughly washed with distilled water to remove acid.

CoPc was purchased from Tokyo Chemical Industry Co., Ltd. It was used without further purification.

LG and CoPc were mixed to make the $\mathrm{Co} / \mathrm{LG}$ weight ratio of $0.01-0.14$. The amount of Co added is expressed by the weight of cobalt to $100 \mathrm{~g}$ of the precursor (owp\%, on the weight of precursor). The mixture was pulverized at $800 \mathrm{rpm}$ for $3 \mathrm{~h}$ using a planetary ball mill (Fritsch, P-7). The pulverized sample was passed through a stainless steel sieve with a mesh size of $106 \mu \mathrm{m}$. Then the

Table 1. Elements contained in Pb2000 before and after acid treatment.

\begin{tabular}{ccc}
\hline Element & $\begin{array}{c}\text { Before acid treatment } \\
(\mathrm{mg} / \mathrm{g})\end{array}$ & $\begin{array}{c}\text { After acid treatment } \\
(\mathrm{mg} / \mathrm{g})\end{array}$ \\
\hline $\mathrm{Al}$ & $60^{\mathrm{a}}$ & $23^{\mathrm{b}}$ \\
$\mathrm{Ca}$ & $110^{\mathrm{a}}$ & $0.5^{\mathrm{b}}$ \\
$\mathrm{Fe}$ & $89^{\mathrm{a}}$ & $1.4^{\mathrm{b}}$ \\
$\mathrm{Mg}$ & $63^{\mathrm{a}}$ & $0.3^{\mathrm{b}}$ \\
$\mathrm{Na}$ & $1300^{\mathrm{a}}$ & $0^{\mathrm{b}}$ \\
$\mathrm{P}$ & $49^{\mathrm{a}}$ & $3^{\mathrm{b}}$ \\
$\mathrm{Ti}$ & $8^{\mathrm{a}}$ & $0.3^{\mathrm{b}}$ \\
$\mathrm{C}$ & $592^{\mathrm{c}}$ & $-{ }^{\mathrm{d}}$ \\
$\mathrm{N}$ & $6^{\mathrm{c}}$ & $-{ }^{\mathrm{d}}$ \\
$\mathrm{H}$ & $59^{\mathrm{c}}$ & $-^{\mathrm{d}}$ \\
\hline
\end{tabular}

${ }^{a}$ Analyzed using ICP by Mitsui Chemical Analysis and Consulting Service, Inc.; ${ }^{b}$ Analyzed by TEM-EDS in our laboratory; ${ }^{\mathrm{c}}$ Analyzed by an organic elemental analyzer in Center for Material Research by Instrumental Analysis, Gunma University; ${ }^{\mathrm{d}}$ Not measured in this study. sample was carbonized on a quartz boat at $1000^{\circ} \mathrm{C}$ for $1 \mathrm{~h}$ under nitrogen flow of $500 \mathrm{~mL} / \mathrm{min}$ at the heating rate of $10^{\circ} \mathrm{C} / \mathrm{min}$. After carbonization, the sample was pulverized again at $750 \mathrm{rpm}$ for $90 \mathrm{~min}$ using the same ball mill and filtered with the same stainless steel sieve. Then 0.5 $\mathrm{g}$ of the sample was washed with $100 \mathrm{~mL}$ of $1 \mathrm{M}$ hydrochloric acid at $70^{\circ} \mathrm{C}$ for $2 \mathrm{~h}$ and filtered with a membrane filter with a pore size of $1 \mu \mathrm{m}$. Acid washing was repeated three times and then the sample was thoroughly washed with distilled water until the washing water became neutral in $\mathrm{pH}$. After drying the sample in a vacuum oven at $80^{\circ} \mathrm{C}$, elements contained in the sample were measured by a transmission electron microscope equipped with EDS (JEOL 2010) as shown in Table 1. Most of the metal elements contained in LG raw material were removed by acid washing. Hereafter a carbon sample expressed LG(3) stands for a carbon prepared from $1 \mathrm{~g} \mathrm{LG}$ and $0.03 \mathrm{~g}$ cobalt. Carbons thus prepared were subjected to the following characterization.

\subsubsection{Phenol-Formaldehyde Resin Based Sample}

One g of phenol-formaldehyde resin (Ph, PSK 2320, GUN EI Chemical Industry Co., Ltd) was dissolved in $500 \mathrm{~mL}$ acetone and mixed with $\mathrm{CoPc}$ to give the $\mathrm{Co} / \mathrm{Ph}$ weight ratio of $3 / 100$. The mixture was ultrasonicated for $30 \mathrm{~min}$, acetone was removed by a rotary evaporator and the sample was dried at $70^{\circ} \mathrm{C}$ under reduced pressure. The obtained carbon precursor was carbonized, pulverized, filtered and washed with acid in the same way described in 2.1.1. Ph-based carbon sample is expressed in the same way with LG-based carbon samples: $\mathrm{Ph}(3)$.

\subsection{Characterization}

Transmission electron microscopic (TEM) observation was carried out for the ground sample placed on a copper grid coated with an amorphous carbon (JEOL). The TEM specimen was prepared by dropping an aliquot amount of the dispersion, which was prepared by ultrasonic dispersion of the carbon in methanol, on the copper grid. After evaporating methanol, the samples were subjected to TEM observations. The TEM equipment was JEM2010 (JEOL) operated at an acceleration voltage of $200 \mathrm{kV}$.

$\mathrm{X}$-ray diffraction (XRD) profiles for the powder samples were obtained using an X-ray diffractometer (XRD6100, SHIMADZU Corp.). The X-ray source was $\mathrm{Cu}-\mathrm{K} \alpha$, with operating conditions of $20 \mathrm{kV}$ and $32 \mathrm{~mA}$. The range of diffraction angle was $2 \theta=5^{\circ}-90^{\circ}$ and the scan speed was $1 \%$ min.

$\mathrm{C} 1 \mathrm{~s}, \mathrm{O} 1 \mathrm{~s}, \mathrm{~N} 1 \mathrm{~s}$ and metal elements such as $\mathrm{Co} 2 \mathrm{p}, \mathrm{Fe}$ $2 p$, Al $2 p$ core-level X-ray photoelectron spectra (XPS) were measured with Kratos AXIS NOVA (SHIMADZU Corp.) spectrometer by using Al-K $\alpha$ X-ray (10 mA, 15 $\mathrm{kV})$. The charge-up shift correction was made by setting 
the $\mathrm{C} 1 \mathrm{~s}$ of the carbonized sample at $284.5 \mathrm{eV}$.

Rotating disk electrode (RDE) voltammetry was employed to assess the ORR activity of the carbons. Normally, a carbon slurry was prepared in the following manner: $5 \mathrm{mg}$ of the carbonized sample was mixed with $50 \mu \mathrm{L}$ of Nafion solution (5\% solution of lower aliphatic alcohols, Aldrich), $150 \mu \mathrm{L}$ of ethanol (99.5\%, Wako Pure Chemicals, Co. Ltd.) and $150 \mu \mathrm{L}$ of ultrapure water in a plastic conical vial $(1.5 \mathrm{~mL})$. The working electrode was a $4 \mathrm{~mm}$ diameter glass-like carbon electrode (BAS Inc.). The slurry $(1.78 \mu \mathrm{L})$ was pasted onto the whole area of the glass-like carbon electrode. The catalytic electrode was obtained after removal of the solvents by drying in the atmosphere. The electrolyte was a $0.5 \mathrm{M} \mathrm{H}_{2} \mathrm{SO}_{4}$ solution. Reversible hydrogen electrode (RHE) and glass-like carbon were used as the reference and counter electrodes, respectively. Prior to the measurements, dissolved oxygen in the acid solution was purged by bubbling nitrogen gas. Cyclic voltammetry measurements were performed by sweeping the potential between $0.0 \mathrm{~V}$ and $1.0 \mathrm{~V}$ vs. RHE at $50 \mathrm{mV} / \mathrm{s}$ for five cycles with a potentiostat (ALS $700 \mathrm{~A}$ or ALS 2323, BAS Inc.). The reference linear sweep voltammograms ( $\mathrm{N}_{2}$-LSVs) were obtained by sweeping the potential from $1.0 \mathrm{~V}$ to $0.0 \mathrm{~V}$ vs. RHE at 1 $\mathrm{mV} / \mathrm{s}$ with the rotating electrode at $1500 \mathrm{rpm}$. The $\mathrm{H}_{2} \mathrm{SO}_{4}$ solution was then bubbled with oxygen gas to obtain $\mathrm{O}_{2}$-saturated acidic medium. The linear sweep voltammograms $\left(\mathrm{O}_{2}\right.$-LSVs $)$ were measured in this solution by sweeping the same potential range as the $\mathrm{N}_{2}$-LSVs. Finally, net voltammograms for ORR were obtained by subtracting $\mathrm{N}_{2}$-LSV from $\mathrm{O}_{2}-\mathrm{LSV}$. The potential was represented by the RHE standard.

\section{Results and Discussion}

\subsection{Carbon Structure}

Figure 1(a) shows typical XRD profiles of the LG-based carbons. The carbon prepared in the absence of $\mathrm{CoPc}$ shows halo diffractions at $2 \theta \sim 23^{\circ}$ and $42^{\circ}$ indicating its amorphous nature. The addition of CoPc resulted in the developments of diffractions. The most prominent developments are observed at $2 \theta \sim 26^{\circ}$. This peak is assigned to 002 diffraction of turbostratic carbon, which is a sign of the formation of NS structure. The development of the peak saturated above $3 \mathrm{owp} \%$ addition of Co.

Close observation of the 002 diffraction of NSCC has revealed that the diffraction is composed of crystalline sharp component and amorphous broad component [1]. Figure 1(b) shows an illustration of the deconvolution of the 002 into two components. The areal fraction of the sharp component out of the total area of this diffraction was defined as $f_{\text {sharp }}$, which has been turned out to be an indicator of the development degree of NS structure [1].

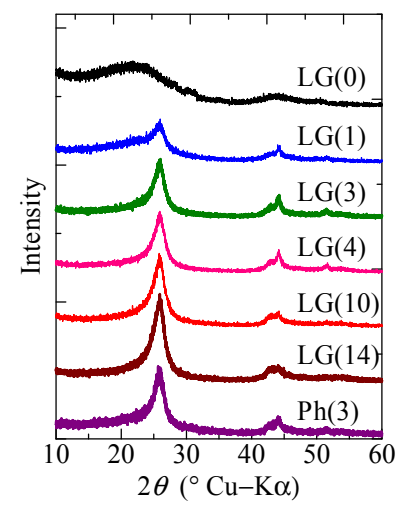

(a)

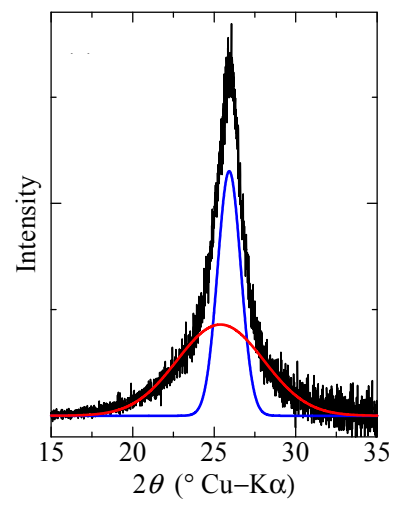

(b)
Figure 1. (a) XRD profiles of LG- and Ph-based samples. (b) Illustration of peak deconvolution into broad (red curve) and sharp (blue curve) components after making corrections of atomic scattering, Lorentz and polarization factors.

Figure 2 shows the relationship between the amounts of Co added and obtained values of $f_{\text {sharp }}$. The value increased up to $3 \mathrm{owp} \%$ of the amount of Co addition then it saturated. The $f_{\text {sharp }}$ value of $\mathrm{Ph}(3)$ had a similar $f_{\text {sharp }}$ value to $\mathrm{LG}(3)$, namely 0.41 and 0.42 for $\mathrm{Ph}(3)$ and LG(3), respectively.

TEM observation gave direct evidence of the formation of NS structure. Figure 3 shows TEM images of some representative samples. $\mathrm{LG}(0)$ showed uniformly amorphous appearance in agreement with the XRD analysis shown in Figure 1(a). LG(1) developed the typical signs of the formation of NS structures by showing small ring-like structures embedded in the amorphous matrix. The magnified image shown in the same figure clearly indicated that the ring-like structure composed of graphitic layers. The occurrence frequency of the structure significantly increased up to $3 \mathrm{owp} \%$ of the amount of Co addition; the frequency seemed constant above 3 owp $\%$ of the Co addition.

We definitely demonstrated the conversion of LG into NSCC by the carbonization in the presence of NS forming catalyst, $\mathrm{CoPc}$ in the present case, likewise for conventional synthetic polymers such as furan resin $[1,2]$, oxine-formaldehyde resin [3], furfuryl alcohol [4-6], and phenol-formaldehyde resin $[7,8]$ that we have employed previously.

\subsection{Electrocatalytic Activity of the Prepared Carbons for Oxygen Reduction Reaction}

Figure 4 shows the ORR voltammograms of the LGbased and Ph-based carbons. The addition of Co to the precursor clearly induced the increases in ORR activity. Here we defined $i_{0.7}$, the ORR current density at $0.7 \mathrm{~V}$ to express the ORR quantitatively, since the current at this potential governed by charge transfer process. Fig- 


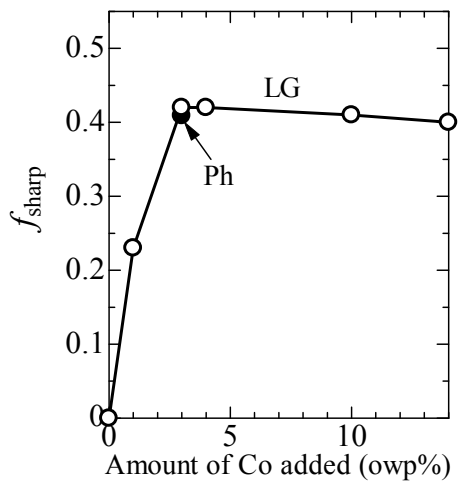

Figure 2. Dependence of $\boldsymbol{f}_{\text {sharp }}$ on the amount of Co added.

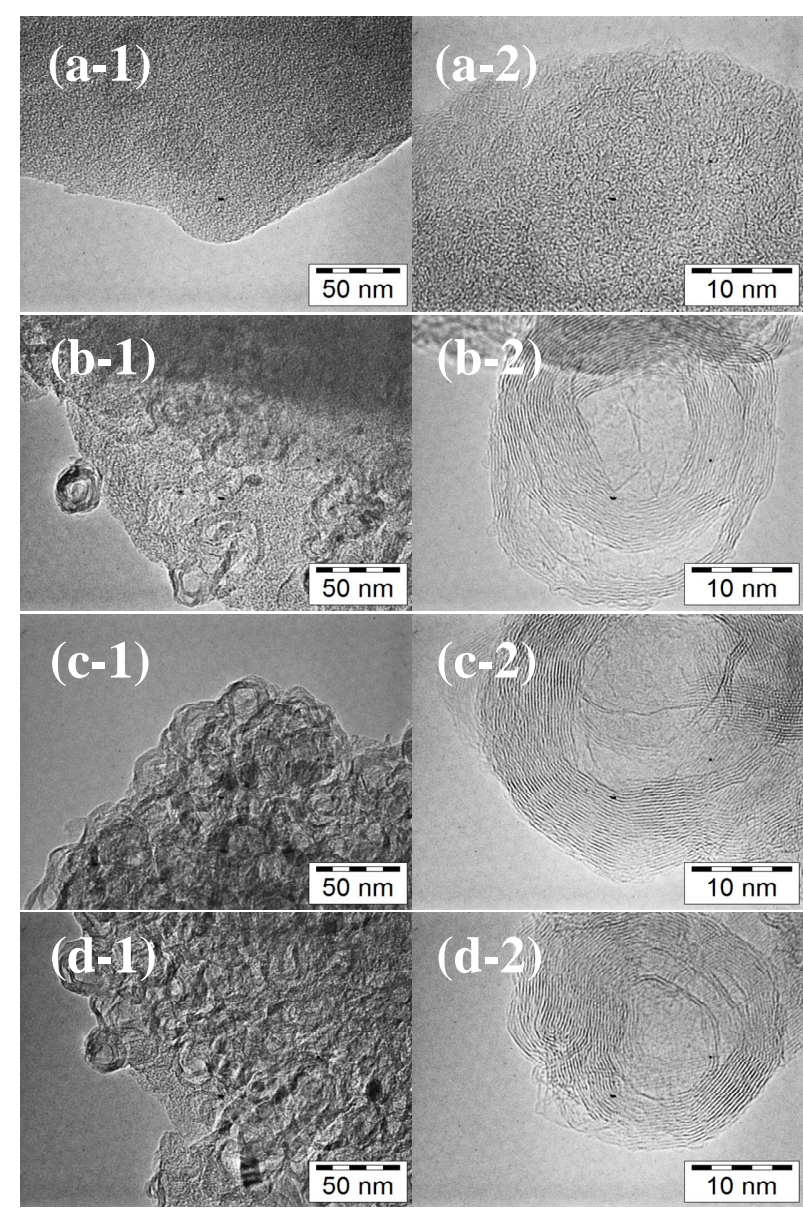

Figure 3. TEM and HR-TEM images of the prepared carbons. (a-1), (a-2): LG(0); (b-1), (b-2): LG(1); (c-1), (c-2): LG(3); (d-1), (d-2): Ph(3).

ure 5 presents the dependence of $i_{0.7}$ on the amount of Co added. The ORR activity represented by $i_{0.7}$ rapidly increased up to 3 owp $\%$ and switched to a gradual increase above it. The participation of the metal species in the ORR catalysis $[18,19]$ seems plausible, however it was denied by XPS measurements $(<0.1$ atom $\%)$. Hence the rapid increase of $i_{0.7}$ below $3 \mathrm{owp} \%$ was ascribed to the

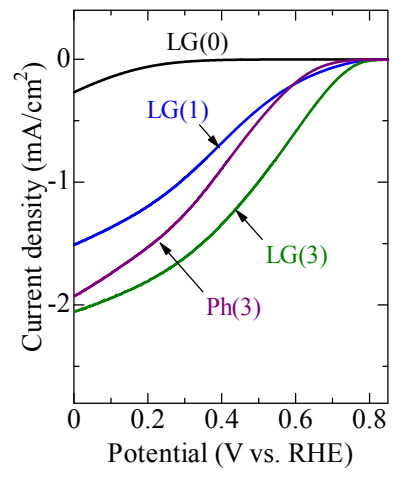

(a)

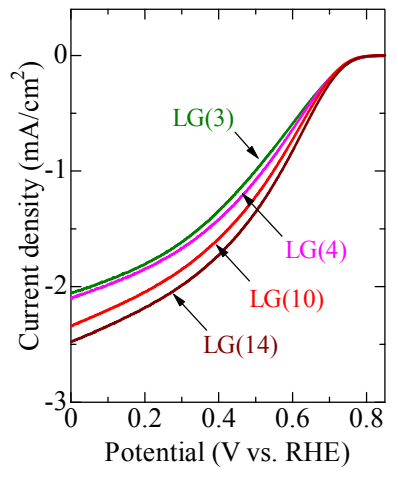

(b)
Figure 4. $\mathrm{O}_{2}$ reduction voltammograms of the prepared carbons. (a) LG-based samples prepared with the amount of Co up to 3 owp\% and Ph-based sample; (b) LG-based samples prepared with the amount of Co above 3 owp\%.

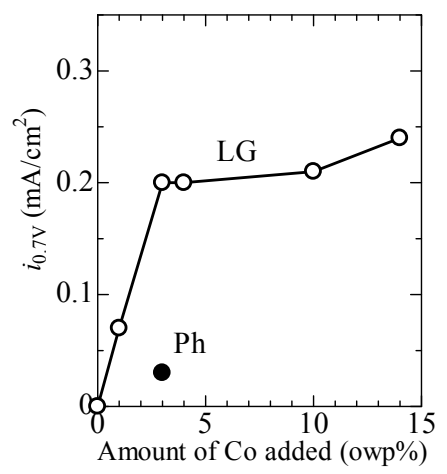

Figure 5. Dependence of $\boldsymbol{i}_{0.7}$ on the amount of Co added.

development of NS structures shown in Figure 2 as we have claimed in the previous studies $[1,6]$.

Figures 4 and 5 include the results of $\mathrm{Ph}(3)$, which had almost the same $f_{\text {sharp }}$ as LG(3) (Figure 2). The $i_{0.7}$ values plotted in Figure 5 demonstrates that the activity of $\operatorname{LG}(3)$ is seven times higher than $\mathrm{Ph}(3)$. States of metal and nitrogen are the possible factors to elucidate the difference in the ORR activities between LG(3) and $\mathrm{Ph}(3)$. XPS did not detect any Co on the surface of $\mathrm{Ph}(3)$ like $\mathrm{LG}(3)$ case, but it detected N/C atomic ratio of 0.013 for $\mathrm{LG}(3)$, which is two times higher than that for $\mathrm{Ph}(3)$ $(\mathrm{N} / \mathrm{C}=0.007)$.

Three types of nitrogen species are discussed by different researchers; i.e. pyridinic nitrogen [20], quarternary-coordinated nitrogen [21] and positively charged nitrogen [22]. In the previous paper, we have observed the enhancement of ORR activity by introducing nitrogen into carbon materials and ascribed it to the introduction of structural defects in graphitic layer [4]. We also reported a restriction of layer growth during the carbonization of a mesophase pitch by fullerene and simultaneous increase in the ORR activity [23]. Further studies will be conducted to elucidate the difference in the ORR activity 
between $\operatorname{LG}(3)$ and $\mathrm{Ph}(3)$.

\section{Conclusion}

The present study was conducted to ensure the possibility of $L G$ as a raw material for preparing NSCC with ORR activity. The study revealed that a type of $L G$ obtained from herbaceous plants was successfully converted into NSCC and showed excellent ORR activity. Furthermore, the ORR activity of the LG-based NSCC was higher than Ph-based NSCC probably due to the higher nitrogen content of the material. In this respect, the LG used here is favorable for preparing NSCC due to intrinsically higher nitrogen content than polymers from fossil resources.

\section{Acknowledgements}

Financial support for this study was provided by the "Advanced Low Carbon Technology Research and Development Program (ALCA)" by Japan Science and Technology Agency (JST) and the "Element Innovation (EI)" by Ministry of Education, Culture, Sports, Science and Technology in Japan (MEXT) The measurement of $\mathrm{X}$-ray photoelectron spectra was performed with the instrument included in Low Carbon Network (LCnet) by MEXT.

\section{REFERENCES}

[1] J. Ozaki, S. Tanifuji, A. Furuichi and K. Yabutsuka, "Enhancement of Oxygen Reduction Activity of Nanoshell Carbons by Introducing Nitrogen Atoms from Metal Phthalocyanines," Electrochimica Acta, Vol. 55, No. 6, 2010, pp. 1864-1871.

[2] J. Ozaki, S. Tanifuji, A. Furuichi and A. Oya, "Enhancement of Oxygen Reduction Activity by Carbonization of Furan Resin in the Presence of Phthalocyanines," Carbon, Vol. 44, No. 7, 2006, pp. 1324-1326. http://dx.doi.org/10.1016/j.enbuild.2011.03.006

[3] N. Kannari and J. Ozaki, "Formation of Uniformly and Finely Dispersed Nanoshells by Carbonization of Cobalt-Coordinated Oxine-Formaldehyde Resin and Their Electrochemical Oxygen Reduction Activity," Carbon, Vol. 50, No. 8, 2012, pp. 2941-2952. http://dx.doi.org/10.1016/j.comnet.2011.07.010

[4] J. Ozaki, N. Kimura, T. Anahara and A. Oya, "Preparation and Oxygen Reduction Activity of BN-Doped Carbons," Carbon, Vol. 45, No. 9, 2007, pp.1847-1853. http://dx.doi.org/10.1016/j.enpol.2009.03.025

[5] J. Ozaki, T. Anahara, N. Kimura and A. Oya, "Simultaneous Doping of Boron and Nitrogen into a Carbon to Enhance its Oxygen Reduction Activity in Proton Exchange Membrane Fuel Cells," Carbon, Vol. 44, No. 15, 2006, pp. 3348-3378.

http://dx.doi.org/10.1016/j.enpol.2009.10.037

[6] J. Ozaki , K. Nozawa, K. Yamada, Y. Uchiyama, Y. Yo- shimoto, A. Furuichi, T. Yokoyama and A. Oya, "Structures, Physicochemical Properties and Oxygen Reduction Activities of Carbons Derived from Ferrocene-Poly(Furfuryl Alcohol) Mixtures," Journal of Applied Electrochemistry, Vol. 36, No. 2, 2006, pp. 239-247. http://dx.doi.org/10.1016/j.enpol.2006.10.014

[7] M. Kobayashi, H. Niwa, M. Saito, Y. Harada, M. Oshima, H. Ofuchi, K. Terakura, T. Ikeda, Y. Koshigoe, J. Ozaki and S. Miyata, "Indirect Contribution of Transition Metal towards Oxygen Reduction Reaction Activity in Iron Phthalocyanine-Based Carbon Catalysts for Polymer Electrolyte," Electrochimica Acta, Vol. 74, 2012, pp. 254-259. http://dx.doi.org/10.1016/j.enpol.2009.12.024

[8] M. Matsui, N. Takahashi and J. Ozaki, "Adsorption of Cytochrome $c$ on Nanoshell Carbon," Carbon, Vol. 49, No. 13, 2011, pp. 4505-4510. http://dx.doi.org/10.1016/j.carbon.2011.06.060

[9] C. Pouteau, P. Dole, B. Cathal, L. Averous and N. Boquillon, "Antioxidant Properties of Lignin in Polypropylene," Polymer Degradation and Stability, Vol. 81, No. 1, 2003, pp. 9-18.

http://dx.doi.org/10.1016/S0141-3910(03)00057-0

[10] A. Garcia, M. G. Alriols, G. Spigno and J. Labidi, "Lignin as Natural Radical Scavenger. Effect of the Obtaining and Purification Processes on the Antioxidant Behaviour of Lignin," Biochemical Engineering Journal, Vol. 67, 2012, pp. 173-185. http://dx.doi.org/10.1016/j.bej.2012.06.013

[11] S. Domenek, A. Louaifi, A. Guinault and S. Baummberger, "Potential of Lgnins as Atioxidant Additive in Active Biodegradable Packaging Materials," Journal of Polymers and the Environment, Vol. 21, No. 3, 2013, pp. 692701.

[12] A. Moubarik, N. Grimi, N. Boussetta and A. Pizzi, "Isolation and Characterization of Lignin from Moroccan Sugar Cane Bagasse: Production of Lignin-Phenol-Formaldehyde Wood Adhesive," Industrial Crops and Products, Vol. 45, 2013, pp. 296-302. http://dx.doi.org/10.1016/j.indcrop.2012.12.040

[13] B. Acemioglu, A. Samil, M. H. Alma and R. Gundogan, "Copper(II) Removal from Aqueous Solution by Organosolv Lignin and Its Recovery," Journal of Applied Polymer Science, Vol. 89, No. 6, 2003, pp. 1537-1541. http://dx.doi.org/10.1002/app.12251

[14] E. Gonzalez-Serrano, T. Cordero, J. Rodriguez-Mirasol, L. Cotoruelo and J. J. Rodriguez, "Removal of Water Pollutants with Activated Carbons Prepared from $\mathrm{H}_{3} \mathrm{PO}_{4}$ Activation of Lignin from Kraft Black Liquors," Water Research, Vol. 38, No. 13, 2004, pp. 3043-3050. http://dx.doi.org/10.1016/j.watres.2004.04.048

[15] K. Babeł and K. Jurewicz, "KOH Activated Lignin Based Nanostructured Carbon Exhibiting High Hydrogen Electrosorption," Carbon, Vol. 46, No. 14, 2008, pp. 19481956. http://dx.doi.org/10.1016/j.carbon.2008.08.005

[16] T. Haensel, A. Comouth, P. Lorenz, S. I.-U. Ahmed, S. Krischok, N. Zydziak, A. Kauffmann and J. A. Schaefer, "Pyrolysis of Cellulose and Lignin," Applied Surface Science, Vol. 255, No. 18, 2009, pp. 8183-8189. http://dx.doi.org/10.1016/j.apsusc.2009.05.047 
[17] J.-Y. Kim, E.-J. Shin, I.-Y. Eom, K. Won, Y. H. Kim, D. Choi, I.-G. Choi and J. W. Choi, "Structural Features of Lignin Macromolecules Extracted with Ionic Liquid from Poplar Wood," Bioresource Technology, Vol. 102, No. 19, 2011, pp. 9020-9025. http://dx.doi.org/10.1016/j.biortech.2011.07.081

[18] M. C. Martins Alves, J. P. Dodelet, D. Guay, M. Ladouceur and G. Tourillon, "Origin of the Electrocatalytic Properties for Oxygen Reduction of Some Heat-Treated Polyacrylonitrile and Phthalocyanine Cobalt Compounds Adsorbed on Carbon Black as Probed by Electrochemistry and X-Ray Absorption Spectroscopy," The Journal of Physical Chemistry, Vol. 96, No. 26, 1992, pp. 1089810905. http://dx.doi.org/10.1021/j100205a054

[19] M. Lefèvre, J. P. Dodelet and P. Bertrand, "Molecular Oxygen Reduction in PEM Fuel Cells: Evidence for the Simultaneous Presence of Two Active Sites in Fe-Based Catalysts," The Journal of Physical Chemistry B, Vol. 106, No. 34, 2002, pp. 8705-8713. http://dx.doi.org/10.1021/jp020267f

[20] P. H. Matter, L. Zhang and U. S. Ozkan, "The Role of
Nanostructure in Nitrogen-Containing Carbon Catalysts for the Oxygen Reduction Reaction," Journal of Catalysis, Vol. 239, No. 1, 2006, pp. 83-96. http://dx.doi.org/10.1016/j.jcat.2006.01.022

[21] T. Ikeda, M. Boero, S. Huang, K. Terakura, M. Oshima and J. Ozaki, "Carbon Alloy Catalysts: Active Sites for Oxygen Reduction Reaction," The Journal of Physical Chemistry C, Vol. 112, No. 38, 2008, pp. 14706-14709. http://dx.doi.org/10.1021/jp806084d

[22] K. Gong, F. Du, Z. Xia, M. Durstock and L. Dai, "Nitrogen-Doped Carbon Nanotube Arrays with High Electrocatalytic Activity for Oxygen Reduction," Science, Vol. 323, No. 5915, 2009, pp. 760-764. http://dx.doi.org/10.1126/science. 1168049

[23] N. Kannari and J. Ozaki, "Formation of Non-Planar Carbon Layers in Naphthalene-Pitch-Derived Carbon by Addition of Fullerene Mixture and Its Influence on Electrochemical Oxygen Reduction Reaction," TANSO, Vol. 2011, No. 248, 2011, pp. 102-104. http://dx.doi.org/10.7209/tanso.2011.102 